\title{
DDX3X Multifunctionally Modulates Tumor Progression and Serves as a Prognostic Indicator to Predict Cancer Outcomes
}

\author{
Tsung-Chieh Lin (1)
}

Genomic Medicine Core Laboratory, Chang Gung Memorial Hospital, Linkou, Taiwan; tclin1980@cgmh.org.tw; Tel.: +886-3-328-1200 (ext. 7722)

Received: 26 November 2019; Accepted: 28 December 2019; Published: 31 December 2019

\begin{abstract}
DEAD (Asp-Glu-Ala-Asp) box polypeptide 3, X-Linked (DDX3X), also known as DDX3, is one of the most widely studied and evolutionarily conserved members of the DEAD-box RNA helicase subfamily, and has been reported to participate in several cytosolic steps of mRNA metabolism. DDX3X facilitates the translation of specific targets via its helicase activity and regulates factors of the translation initiation complex. Emerging evidence illustrates the biological activities of DDX3X beyond its originally identified functions. The nonconventional regulatory effects include acting as a signaling adaptor molecule independent of enzymatic RNA remodeling, and DDX3X exhibits abnormal expression in cancers. DDX3X interacts with specific components to perform both oncogenic and tumor-suppressive roles in modulating tumor proliferation, migration, invasion, drug resistance, and cancer stemness in many types of cancers, indicating the need to unravel the associated molecular mechanisms. In this review article, we summarized and integrated current findings relevant to DDX3X in cancer research fields, cytokines and compounds modulating DDX3X's functions, and the released transcriptomic information and cancer patient clinical data from public databases. We found evidence for DDX3X having multiple impacts on cancer progression, and evaluated DDX3X expression levels in a pancancer panel and its associations with patient survival in each cancer-type cohort.
\end{abstract}

Keywords: DDX3X; cancer progression; clinical outcomes

\section{Introduction}

DEAD (Asp-Glu-Ala-Asp) box polypeptide 3, X-Linked (DDX3X) is a member of the DEAD-box family of RNA helicases and has been reported to be involved in double-stranded RNA unwinding [1], pre-mRNA splicing [2], RNA export [3], transcription [4], and translation [5-7]. Recently, the helicase activity of DDX3X was reported to repress the repeat-associated non-AUG translation of GGGGCC repeats in C9ORF72 via direct binding, thereby reducing the aberrant accumulation of dipeptide repeat that might be likely to ameliorate amyotrophic lateral sclerosis (ALS) and frontotemporal dementia (FTD) [8]. Various previously identified DDX3X variants were represented, along with distinct protein domains (Figure 1) [9]. Actually, prevalence of $D D X 3 X$ somatic mutations has been found in cancer patients [10-12]. In a chronic lymphocytic leukemia cohort, all identified DDX3X mutations were truncating mutations, including nonsense mutations or frameshift indels [13]. Twenty-one out of 105 cases of natural killer/T-cell lymphoma also showed recurrent DDX3X somatic mutations leading to impaired RNA-unwinding function [14]. Somatic evolution due to the accumulation of genomic changes may alter cancer development and progression, including drug resistance and cell proliferation. In a gene gravity model, tumor genomes harboring DDX3X nonsynonymous somatic mutations appear to have high mutation density [15]. Emerging evidence indicates the critical regulatory role of DDX3X in cancer progression. Due to its complicated function in RNA metabolism, DDX3X has gained increasing 
attention for its biological functions in various types of cancers and has been shown to modulate cancer progression in a complex manner. This complexity was further increased by evidence revealing that DEAD box proteins generally do not function alone but instead act as components of multiprotein complexes [16]. The exact function of DDX3X is affected by its interacting partners and is tumor and/or context dependent [17]. DDX3X is characterized as a multifunctional RNA helicase that regulates RNA metabolism via direct binding with RNA targets. In breast cancer, DDX3X directly interacts with KLF4 mRNA and regulates its splicing [18]. RNA G-quadruplexes (rG4s) are a secondary structure of mRNAs known to influence posttranscriptional mechanisms involving RNAs. A recent report further showed that a systematic affinity proteomics approach identified several high-confidence interactors, including DDX3X, which could assemble into the rG4 located in the $5^{\prime}$-untranslated region (UTR) of the NRAS oncogene transcript. Furthermore, the interaction of $5^{\prime}$-UTR rG4-containing transcripts was decreased upon mutation of the DDX3X glycine-arginine (GAR) domain [19]. Both tumor-promotive and tumor-suppressive effects of DDX3X have been identified and reported. These controversial results emphasize the urgent need to clarify the prognostic value of DDX3X and to unravel the molecular mechanisms specifically involved in human cancer types. Therefore, we summarized and integrated evidence demonstrating DDX3X expression levels in a broad range of cancer types together with DDX3X-mediated effects on the regulation of several critical factors in processes related to cancer progression, including tumor proliferation, metastasis, drug resistance, and cancer stemness. In this review, we focus on the biological function of DDX3X in cancer, and further illustrate its clinical significance on a pancancer scale.

\section{Human $D D X 3 X$ isoform view}

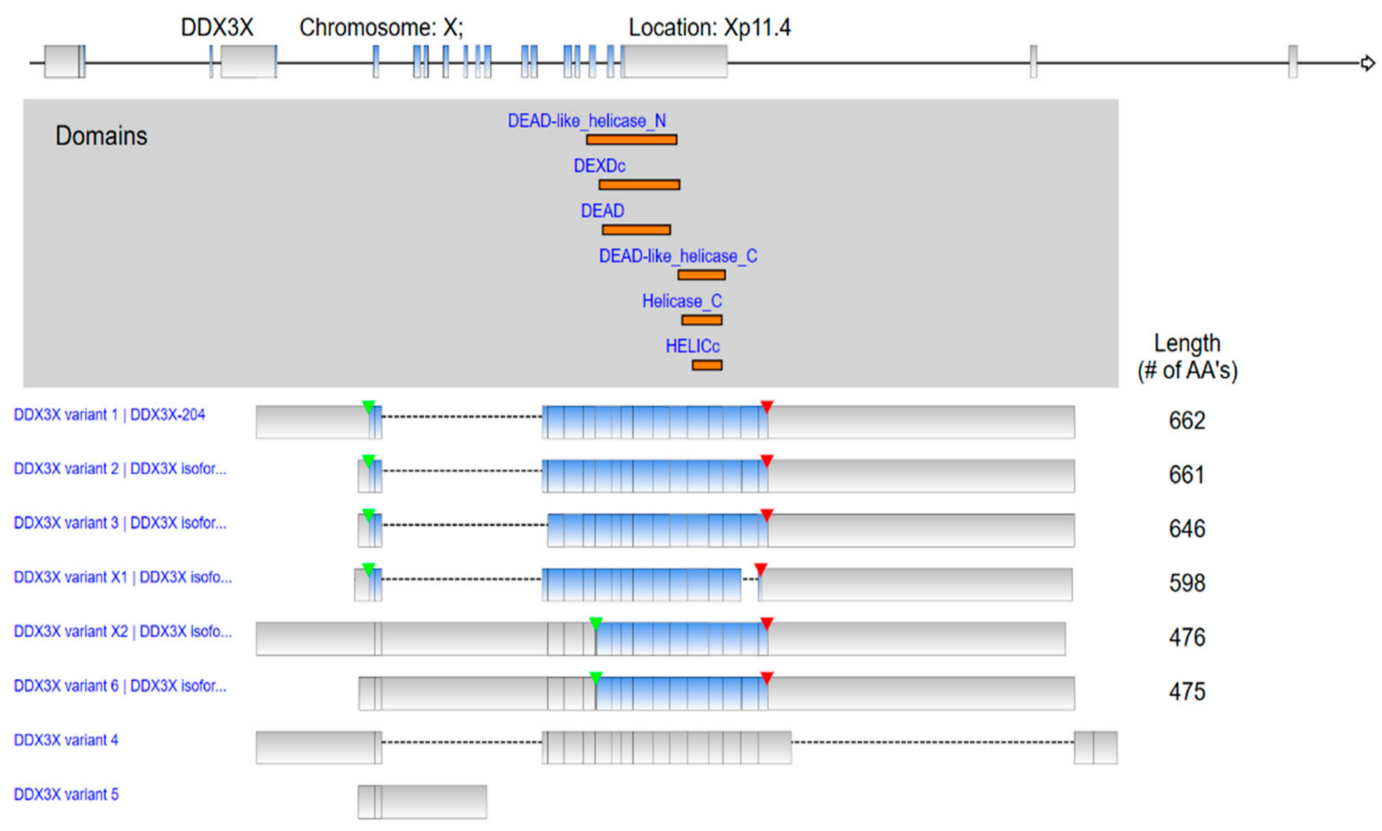

Figure 1. Human DDX3X isoform view from RefSeq. Data were analyzed by using ingenuity pathway analysis (IPA). Protein domains of various DDX3X isoforms are marked and located by orange color. The start of transcription and the position of a stop codon are indicated by green and red arrowheads, respectively.

\section{DDX3X Expression in Cancers}

The relative expression of DDX3X in various cancer types demonstrates its pivotal role in tumor progression. In colorectal cancer, DDX3X expression has been detected, and positive associations between DDX3 and KRAS, YAP1, and SIX2 have been observed in KRAS wild-type patients [20]. In addition, increased cytoplasmic DDX3X expression has been observed in breast cancer metastases, especially in 
triple-negative and high-grade cases [21]. A comparison of matched tumor and normal tissue further indicated that the DDX3 level was obviously higher in pancreatic ductal adenocarcinoma tissue than in peritumoral tissue, benign pancreatic tissue, and normal pancreatic tissue $(p<0.01)$ [22]. DDX3X overexpression has been reported in prostate cancers, and overexpression was found to be directly associated with high Gleason scores [23]. Furthermore, an investigation of DDX3X protein levels in 303 colorectal cancer samples evaluated by immunohistochemistry revealed that $39 \%$ of tumors exhibited DDX3X overexpression and that high cytoplasmic DDX3 expression appeared to associate with nuclear $\beta$-catenin expression, suggesting the potential involvement of Wnt signaling [24]. A comprehensive program analyzing the combination of multicancer transcriptomic data and matched clinical information was launched by the University of California Santa Cruz $(n=12,839)$ [25]. These transcriptomic data were mainly generated by microarray experiments and RNA sequencing (RNA-Seq) on a pancancer scale and retrieved from the public database The Cancer Genome Atlas (TCGA). The results showed DDX3X expression after normalization in various types of cancer (Figure 2). DDX3X is relatively highly expressed in stomach adenocarcinoma, kidney clear cell carcinoma, breast invasive carcinoma, cervical and endocervical cancer, esophageal carcinoma, and head and a sub-population of neck squamous cell carcinomas. Additionally, note that the lower DDX3X levels were displayed in uveal melanoma, diffuse large B-cell lymphoma, thymoma, liver hepatocellular carcinoma, kidney papillary cell carcinoma, and skin cutaneous melanoma, which indicates that DDX3X might has a dual role in cancer progression.

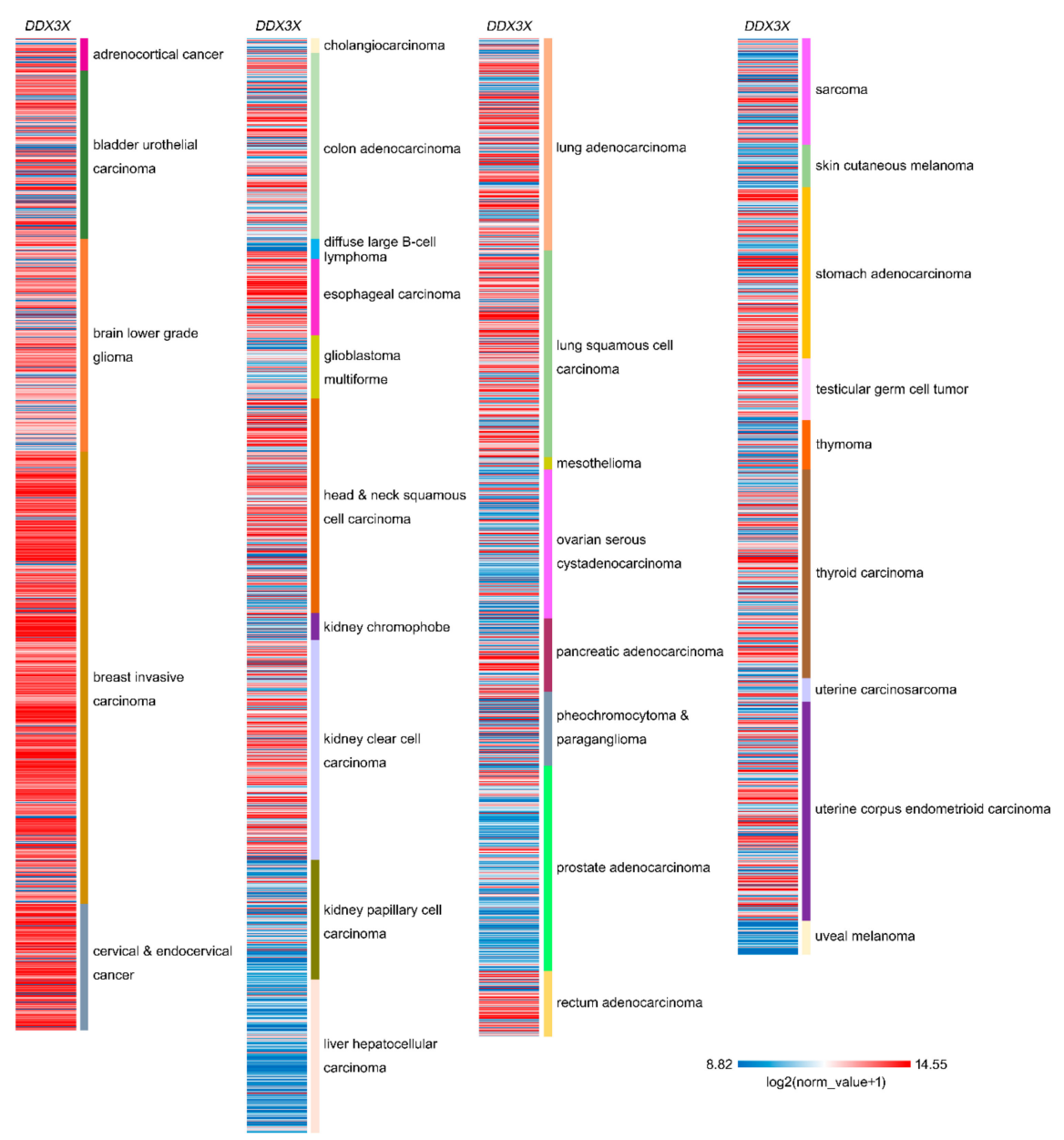

Figure 2. Relative DDX3X expression in a pancancer panel. In a pancancer dataset from The Cancer Genome Atlas, DDX3X expression levels were presented separately for 32 cancer types. The red color in the heat map represents genes with high expression. The blue color in the heat map represents genes with low expression. 


\section{Correlations with Clinical Outcome}

The correlation of DDX3X with clinical prognosis has been evaluated in various types of cancer. Both KRAS wild-type and mutant cohorts of colorectal cancer patients were shown to exhibit high DDX3X expression associated with poor overall survival and relapse-free survival [20]. Associations with poor overall survival and relapse-free survival have also been reported for colorectal cancer cohorts comprising 145 cases [26] and 75 cases [27]. In addition, relatively poor overall survival has been reported for a cohort of 79 breast patients with distant metastasis expressing high DDX3 (hazard ratio (HR) 1.79, $p=0.039$ ) [21]. Similar observations were uncovered in another breast cancer cohort study, in which 35\% of the breast cancer patients displayed high DDX3X levels that correlated with poor clinical outcomes [28]. Furthermore, the prognostic power of DDX3X has been specifically correlated with the nuclear DDX3X expression level in both breast and colorectal cancers [29]. In head and neck squamous cell carcinoma patients, the DDX3X level correlates with lymph node metastasis and a poor prognosis [30]. Another study of pancreatic ductal adenocarcinoma further showed that positive DDX3X expression was correlated with poor outcomes by Kaplan-Meier survival analysis $(p<0.001)$, and the data from Cox multivariate analysis also indicated that DDX3 was an independent poor prognostic factor in cancer patients [22]. However, several research teams have also demonstrated that DDX3X is a biomarker of a good prognosis in cancers. Patients with low DDX3 expression were reported to have worse survival and higher relapse rates than those with high DDX3X expression in a non-small cell lung cancer cohort [31]. In colorectal cancer, high DDX3X protein levels were shown to predict good overall survival and recurrence-free survival in a 221-case cohort, and the RNA expression of DDX3X had significant prognostic value when evaluated by RNA-Seq and microarray platforms [32]. Furthermore, DDX3X expression profiles determined by microarray and RNA-Seq technologies have been analyzed together with clinical follow-up data from public databases including The Human Protein Atlas/The Pathology Atlas [33-37], SurvExpress [38], the TCGA [25], and the Kaplan-Meier plotter database [39], which illustrates the prognostic value of DDX3X in specific cancer types (Table 1). DDX3X is a poor prognostic marker in cohorts of liver cancer, pancreatic cancer, breast cancer, and ovarian cancer, while patients of colorectal cancer, urothelial cancer, lung cancer, and gastric cancer expressing high $D D X 3 X$ level associate with better outcomes. Another human genome DDX3-gene-coded homolog is DDX3Y. The correlation with cancer survival outcome is also listed for comparison (Table 2). Patients expressing high DDX3Y associate with poor outcomes in cohorts of thyroid cancer, lung cancer, colorectal cancer, stomach cancer, prostate cancer, and melanoma. In contrast, $D D X 3 Y$ is a good prognostic biomarker in head and neck cancer, pancreatic cancer, and gastric cancer. 
Table 1. The correlation of $D D X 3 X$ with cancer patient survival.

\begin{tabular}{|c|c|c|c|c|c|c|c|c|}
\hline Symbol & Cancer Type & Prognosis & Endpoint & $p$ Value & Case & Dataset & Method & Probe ID \\
\hline$D D X 3 X$ & Glioma & - & Overall survival & N.S. & 153 & TCGA & RNA Seq & \\
\hline$D D X 3 X$ & Thyroid Cancer & - & Overall survival & N.S. & 501 & TCGA & RNA Seq & \\
\hline$D D X 3 X$ & Lung Cancer & - & Overall survival & N.S. & 994 & TCGA & RNA Seq & \\
\hline$D D X 3 X$ & $\begin{array}{c}\text { Colorectal } \\
\text { Cancer }\end{array}$ & Good & Overall survival & 0.008 & 597 & TCGA & RNA Seq & \\
\hline$D D X 3 X$ & $\begin{array}{l}\text { Head and Neck } \\
\text { Cancer }\end{array}$ & - & Overall survival & N.S. & 499 & TCGA & RNA Seq & \\
\hline$D D X 3 X$ & Stomach Cancer & - & Overall survival & N.S. & 354 & TCGA & RNA Seq & \\
\hline$D D X 3 X$ & Liver Cancer & Poor & Overall survival & 0.001 & 365 & TCGA & RNA Seq & \\
\hline$D D X 3 X$ & $\begin{array}{c}\text { Pancreatic } \\
\text { Cancer }\end{array}$ & Poor & Overall survival & 0.033 & 176 & TCGA & RNA Seq & \\
\hline$D D X 3 X$ & Renal Cancer & - & Overall survival & N.S. & 877 & TCGA & RNA Seq & \\
\hline$D D X 3 X$ & $\begin{array}{l}\text { Urothelial } \\
\text { Cancer }\end{array}$ & Good & Overall survival & 0.029 & 406 & TCGA & RNA Seq & \\
\hline$D D X 3 X$ & Prostate Cancer & - & Overall survival & N.S. & 494 & TCGA & RNA Seq & \\
\hline$D D X 3 X$ & Testis Cancer & - & Overall survival & N.S. & 134 & TCGA & RNA Seq & \\
\hline$D D X 3 X$ & Breast cancer & Poor & Overall survival & 0.024 & 1075 & TCGA & RNA Seq & \\
\hline$D D X 3 X$ & Cervical Cancer & - & Overall survival & N.S. & 291 & TCGA & RNA Seq & \\
\hline$D D X 3 X$ & $\begin{array}{l}\text { Endometrial } \\
\text { Cancer }\end{array}$ & - & Overall survival & N.S. & 541 & TCGA & RNA Seq & \\
\hline$D D X 3 X$ & Ovarian Cancer & - & Overall survival & N.S. & 373 & TCGA & RNA Seq & \\
\hline$D D X 3 X$ & Melanoma & - & Overall survival & N.S. & 102 & TCGA & RNA Seq & \\
\hline$D D X 3 X$ & Breast cancer & Poor & $\begin{array}{c}\text { Relapse-free } \\
\text { survival }\end{array}$ & $<0.001$ & 3951 & $\begin{array}{c}\text { E-MTAB-365, E-TABM-43, GSE: } 11121, \\
12093,\end{array}$ & Array & 201210_at \\
\hline
\end{tabular}


Table 1. Cont.

\begin{tabular}{|c|c|c|c|c|c|c|c|c|}
\hline Symbol & Cancer Type & Prognosis & Endpoint & $p$ Value & Case & Dataset & Method & Probe ID \\
\hline & & & & & & $\begin{array}{c}12276,1456,16391,16446,16716,17705 \\
17907, \\
18728,19615,20194,20271,2034,20685 \\
20711, \\
21653,2603,26971,2990,31448,31519 \\
32646 \\
3494,37946,41998,42568,45255,4611 \\
5327, \\
6532,7390,9195\end{array}$ & & \\
\hline$D D X 3 X$ & Ovarian cancer & Poor & $\begin{array}{l}\text { Post progression } \\
\text { survival }\end{array}$ & $<0.001$ & 1435 & $\begin{array}{c}\text { GSE: } 14764,15622,18520,19829,23554, \\
26193, \\
\text { 26712, 27651, 30161, 3149, 51373, 63885, } \\
\text { 65986, } \\
\text { 9891, TCGA }(n=565)\end{array}$ & $\begin{array}{c}\text { Array } \\
\text { RNA Seq }\end{array}$ & 201210_at \\
\hline$D D X 3 X$ & Lung cancer & Good & $\begin{array}{l}\text { Post progression } \\
\text { survival }\end{array}$ & 0.015 & 344 & $\begin{array}{l}\text { CAARRAY, GSE: } 14814,19188,29013, \\
30219 \\
31210,3141,31908,37745,43580,4573 \\
50081, \\
8894, \text { TCGA }(n=133)\end{array}$ & $\begin{array}{c}\text { Array } \\
\text { RNA Seq }\end{array}$ & 201210_at \\
\hline$D D X 3 X$ & Gastric cancer & Good & $\begin{array}{l}\text { Post progression } \\
\text { survival }\end{array}$ & $<0.001$ & 499 & $\begin{array}{c}\text { GSE: } 14210,15459,22377,29272,51105, \\
62254\end{array}$ & Array & 201210_at \\
\hline
\end{tabular}


Table 2. The correlation of DDX3Y with cancer patient survival.

\begin{tabular}{|c|c|c|c|c|c|c|c|c|}
\hline Symbol & Cancer Type & Prognosis & Endpoint & $p$ Value & Case & Dataset & Method & Probe ID \\
\hline DDX3Y & Glioma & - & Overall survival & N.S. & 153 & TCGA & RNA Seq & \\
\hline DDX3Y & Thyroid Cancer & Poor & Overall survival & 0.027 & 501 & TCGA & RNA Seq & \\
\hline DDX3Y & Lung Cancer & Poor & Overall survival & 0.047 & 994 & TCGA & RNA Seq & \\
\hline DDX3Y & $\begin{array}{l}\text { Colorectal } \\
\text { Cancer }\end{array}$ & Poor & Overall survival & 0.039 & 597 & TCGA & RNA Seq & \\
\hline DDX3Y & $\begin{array}{l}\text { Head and Neck } \\
\text { Cancer }\end{array}$ & Good & Overall survival & $<0.001$ & 499 & TCGA & RNA Seq & \\
\hline DDX3Y & Stomach Cancer & Poor & Overall survival & 0.003 & 354 & TCGA & RNA Seq & \\
\hline DDX3Y & Liver Cancer & - & Overall survival & N.S. & 365 & TCGA & RNA Seq & \\
\hline DDX3Y & $\begin{array}{c}\text { Pancreatic } \\
\text { Cancer }\end{array}$ & Good & Overall survival & 0.042 & 176 & TCGA & RNA Seq & \\
\hline DDX3Y & Renal Cancer & - & Overall survival & N.S. & 877 & TCGA & RNA Seq & \\
\hline DDX3Y & $\begin{array}{l}\text { Urothelial } \\
\text { Cancer }\end{array}$ & - & Overall survival & N.S. & 406 & TCGA & RNA Seq & \\
\hline DDX3Y & Prostate Cancer & Poor & Overall survival & 0.034 & 494 & TCGA & RNA Seq & \\
\hline DDX3Y & Testis Cancer & - & Overall survival & N.S. & 134 & TCGA & RNA Seq & \\
\hline DDX3Y & Breast cancer & N/A & Overall survival & N/A & 1075 & TCGA & RNA Seq & \\
\hline DDX3Y & Cervical Cancer & N/A & Overall survival & N/A & 291 & TCGA & RNA Seq & \\
\hline DDX3Y & $\begin{array}{l}\text { Endometrial } \\
\text { Cancer }\end{array}$ & N/A & Overall survival & N/A & 541 & TCGA & RNA Seq & \\
\hline DDX3Y & Ovarian Cancer & N/A & Overall survival & N/A & 373 & TCGA & RNA Seq & \\
\hline DDX3Y & Melanoma & Poor & Overall survival & 0.022 & 102 & TCGA & RNA Seq & \\
\hline
\end{tabular}


Table 2. Cont

\begin{tabular}{|c|c|c|c|c|c|c|c|c|}
\hline Symbol & Cancer Type & Prognosis & Endpoint & $p$ Value & Case & Dataset & Method & Probe ID \\
\hline$D D X 3 Y$ & Breast cancer & N/A & $\begin{array}{l}\text { Relapse-free } \\
\text { survival }\end{array}$ & N/A & 3951 & $\begin{array}{c}\text { E-MTAB-365, E-TABM-43, GSE: 11121, 12093, } \\
\text { 12276, 1456, 16391, 16446, 16716, 17705, 17907, } \\
\text { 18728, 19615, 20194, 20271, 2034, 20685, 20711, } \\
21653,2603,26971,2990,31448,31519,32646, \\
3494,37946,41998,42568,45255,4611,5327, \\
6532,7390,9195\end{array}$ & Array & 205001_s_at \\
\hline DDX3Y & Ovarian cancer & N/A & $\begin{array}{c}\text { Post progression } \\
\text { survival }\end{array}$ & $\mathrm{N} / \mathrm{A}$ & 1435 & $\begin{array}{c}\text { GSE: } 14764,15622,18520,19829,23554,26193, \\
\text { 26712, 27651, 30161, 3149, 51373, 63885, 65986, } \\
\text { 9891, TCGA }(n=565)\end{array}$ & $\begin{array}{c}\text { Array } \\
\text { RNA Seq }\end{array}$ & 205001_s_at \\
\hline DDX3Y & Lung cancer & - & $\begin{array}{c}\text { Post progression } \\
\text { survival }\end{array}$ & N.S. & 344 & $\begin{array}{l}\text { CAARRAY, GSE: } 14814,19188,29013,30219 \\
\text { 31210, 3141, 31908, 37745, 43580, 4573, 50081, } \\
\text { 8894, TCGA }(n=133)\end{array}$ & $\begin{array}{c}\text { Array } \\
\text { RNA Seq }\end{array}$ & 205001_s_at \\
\hline$D D X 3 Y$ & Gastric cancer & Good & $\begin{array}{c}\text { Post progression } \\
\text { survival }\end{array}$ & $<0.001$ & 499 & GSE: 14210, 15459, 22377, 29272, 51105, 62254 & Array & 205001_s_at \\
\hline
\end{tabular}

Survival data was collected from database SurvExpress, TCGA, and Kaplan-Meier plotter. N.S.—no significance. N/A: a collection of DDX3Y data is not available from female tissues. "-"-no statistically significance. 


\section{DDX3X and Cancer Cell Proliferation}

The role of DD3X in normal cells was characterized by benzo[a]pyrene diol epoxide-activated DDX3X contributing to increased cell proliferation in breast epithelial cells [40]. DDX3X appears to regulate cancer proliferation and tumorigenesis, and both oncogenic and tumor suppressor roles have been uncovered. In a study, depletion of DDX3X led to the inhibition of MCF7 cell proliferation via G1 phase arrest. DDX3X was notably found to reduce the expression of the cell cycle repressor KLF4, indicating the oncogenic role of DDX3X in breast cancer [18]. In addition, DDX3 silencing in the aggressive prostate cancer cell lines DU145 and 22Rv1 results in a significant reduction in tumor clonogenicity. Targeting DDX3X through blocking its ATP binding domain with the small molecule RK-33 synergizes with radiotherapy to decrease tumor cells proliferation in vitro and in xenograft models in vivo [23]. Loss of DDX3X function induced by shRNA or RK-33 addition elicits G1 cell cycle arrest and apoptosis in lung cancer that impairs Wnt signaling [41]. In breast cancer MCF-7 and MDA-MB-231 cell models, a biological reduction in the DDX3X level by shRNA induces decreased proliferation rates and clonogenicity, while reduced tumor volume is seen in animal experiments [42]. Moreover, DDX3X silencing by siRNA causes reductions in both TCF-4 reporter activity and TCF-4-mediated modulation of downstream target genes in colorectal cancer, which leads to reduced proliferation and G1 arrest [24]. The role of the YEATS4/TCEA1/DDX3 axis in hepatocellular carcinoma progression has been explored. The DDX3X protein is stabilized by TCEA1, which promotes hepatocellular carcinoma cell proliferation and colony formation [43]. In contrast, several studies have demonstrated a critical role for DDX3X in repressing cancer cell growth. One report showed that DDX3X participated in replicative stress in the liver. In a study utilizing a hepatocyte-specific DDX3X knockout mouse model, loss of DDX3X expression elicited liver tumorigenesis and liver cell proliferation due to decreases in the expression of two DNA repair factors, DDB2 and XPA [44]. The antitumor activity of rottlerin in hepatocellular carcinoma cells has been suggested to occur in a DDX3X-dependent manner that causes cell cycle arrest in the G1 phase. Upregulation of DDX3X expression, leading to an increase in the p21 level and cyclin D1 downregulation, has been observed after rottlerin treatment [45]. Furthermore, in non-small cell lung cancer, loss of DDX3X expression by p53 inactivation results in tumor malignancy that can be seen as an increase in soft-agar growth [31]. In a similar study, a putative p53 binding site in the DDX3X promoter was identified, and the promotion of cancer cell proliferation was observed to be caused by DDX3X deregulation caused by the E6-inactivated p53 pathway [46]. Immunofluorescence data revealed DDX3X location at centrosome, and further observed its colocalization with p53 at cell cycle mitosis phase in HCT116 and U2OS cells. DDX3X silencing resulted in repression of p53 transcription and defects in chromosome alignment, leading to G2/M phase arrest and cell death [47].

\section{DDX3X and Cancer Cell Metastasis}

Emerging studies illustrating the role of DDX3X in cancer metastasis have been reported. The DDX3X expression level has been found to be positively associated with hypoxia-related proteins, including HIF1 alpha, in invasive breast cancer, suggesting a pro-metastatic role for DDX3X [48]. In a study of melanoma, DDX3X appeared to activate translational reprogramming of MITF mRNA, leading to a proliferative-to-metastatic phenotypic switch in vivo [49]. Furthermore, DDX3X specifically increases the binding of the cap-binding complex (CBC) to the uORF of ATF4 mRNA, which leads to the recruitment of eIF3 and facilitates translation in oral squamous cell carcinoma cell invasion and metastasis [30]. In particular, cytoplasmic DDX3X levels in prostate cancer tissue samples have been associated with cancer metastasis status, and repression of DDX3X via genetic and pharmacologic methods reduces cell motility [50]. Specific shRNA-mediated DDX3X reduction suppresses breast cancer metastasis in vivo [42]. In medulloblastoma, DDX3X also appears to augment cell mobility by increasing Rac1 mRNA translation and stabilizing the $\beta$-catenin protein, suggesting DDX3X has a role in Wnt signaling [51]. Furthermore, the $\beta$-catenin/ZEB1 axis is activated by DDX3X-dependent KRAS transcription to promote colorectal cancer invasion [26]. In addition, the CK1 $1 / D v 12 / \beta$-catenin 
axis was shown to be activated upon DDX3X overexpression to increase colorectal cancer invasion and metastasis in an animal model, whereas these effects could be blocked by inhibitors of CK1 $1 \varepsilon$ (PF4800567) and $\beta$-catenin/TCF signaling (XAV939) [27]. Data from a recent study further showed the binding of DDX3X with circular RNA, circ-CTNNB1, to facilitate cancer invasion and metastasis in gastric cancer via the transactivation of $Y Y 1$ and activation of downstream $\beta$-catenin signaling [52]. However, the results from several studies have also demonstrated that DDX3X can have a role in suppressing cancer metastasis. Depletion of DDX3X expression in liver cancer cells HepG2 increased cell migration ability, and the phenotype was reversed upon restoration of tumor-suppressive miR-200b, miR-200c, miR-122, and miR-145, respectively [53]. Relevant evidence has revealed DDX3X upregulation in diosgenin-inhibited cell migration and invasion in two liver cancer cell lines, HepG2 and SMMC-7721, along with alterations in the expression of the metastasis-related biomarkers $\beta$-catenin and E-cadherin [54]. Moreover, direct modulation of DDX3X to Slug/E-cadherin signaling axis has been shown to repress invasion in lung cancer [31]. In a colorectal cancer, knocking down DDX3X expression promoted cancer cell migration and invasion, and increased tumor metastasis in an animal model via the regulation of the Snail/E-cadherin pathway [32].

\section{DDX3X and Drug Resistance}

DDX3X likely participates in imatinib-resistant chronic myeloid leukemia. Liquid chromatography -mass spectroscopy (LC-MS)/MS data indicate an increased protein level of DDX3X upon imatinib analog (SK23 and Y18) treatments designed to inhibit Bcr-Abl tyrosine kinases [55]. Lung cancer cells harboring EGFR exon 19 deletion and DDX3X cDNA have been observed to have reduced EGFR-tyrosine kinase inhibitor (TKI) sensitivity and cancer stem cell phenotypes, suggesting a role for DDX3X in drug resistance acquisition [56]. In addition, DDX3X-dependent aggressiveness and drug resistance to cetuximab treatment have been revealed to be modulated by the YAP1-SIX2 signaling axis in KRAS wild-type colorectal cancer in both cell and animal models [20]. On the other hand, the tumor suppressor role of DDX3X has been characterized: silencing of DDX3X expression in hepatocellular carcinoma HepG2 cells promoted chemoresistance to anti-cancer drugs doxorubicin and 5-fluorouracil [53].

\section{DDX3X and Cancer Stemness}

The presence of cancer stem cells is one of factors leading to cancer progression. The role of DDX3X in stem cell maintenance and embryonic carcinoma formation has been explored. DDX3X expression at an early stage of embryonic development, especially in undifferentiated stem cells, was detected. DDX3X depletion induced terminal differentiation of lineages, and the potency for teratoma formation was repressed [57]. However, reduction of DDX3X was further reported to induce self-renewal capability and co-expression of stemness gene signature in liver cancer [53]. Furthermore, the engineered DDX3X mutation in neuroepithelial stem cells isolated from Gorlin syndrome patients induced medulloblastoma in orthotopic transplantation model [58]. Those findings further support the opposite point of view regarding DDX3X-mediated cancer stemness and tumor progression.

\section{DDX3X Modulations by Cytokines and Compounds}

In addition to the DDX3X helicase activity inhibitors (Rottlerin, NZ51, RK-33) mentioned above, results from recent studies reveal that cytokines and compounds appear to regulate DDX3X and relevant phenotypes in tumor progression, which further indicates the potential values for designing cancer therapeutic strategy. FE15 and FE109 are ATP-competitive inhibitors proven to block helicase and ATPase function of DDX3X. The compounds possess activity that decreases HIV viral load in peripheral blood mononuclear cells [59]. In addition, doxorubicin is identified as a DDX3X inhibitor: the binding to unique amino acid residue Thr 198 and common amino acid residues Tyr 200 and Thr 201 has been characterized by an in-silico molecular docking approach. Treatment of doxorubicin in oral squamous cell carcinoma H357 cells showed the decrease in inorganic phosphate (Pi) release, ATP hydrolysis, DDX3X downregulation, and the anticancer activity, which was evaluated by MTT 
method [60]. Ketorolac salt is another bioactive compound selected from high throughput virtual screening. Ketorolac salt was found to interact with DDX3X and revealed the growth inhibitory effect in oral cancer cell model [61]. In liver hepatocellular HepG2 cells, treatment with 5-aza-2'-deoxycytidine (decitabine), SP2509, EPZ-6438 (tazemetostat), and TSA (trichostatin A) resulted in the reduced expression of DDX3X at the RNA level [62]. Furthermore, 1,3,4-thiadiazole is a novel DDX3X ATPase activity inhibitor synthesized for countering HIV-1 effects [63]. IL17-DDX3X-Zc3h12a signaling axis might modulate inflammation in cancer microenvironment. IL17 stimulus facilitated the formation of a DDX3X-CIKS complex which is required for the stabilization of Zc3h12a mRNA [64]. Zc3h12a has been pointed out to negatively regulate cellular inflammation in many ways. Zc3h12a led to the mRNA degradation of cytokine IL- 6 and IL-12p40 [65,66]. In human monocyte-derived macrophages, the IL-1 $\beta$, LPS- and TNF- $\alpha$-dependent NF- $\mathrm{kB}$, and JNK signaling pathways were blocked by Zc3h12a [67]. In liver hepatocellular cells, 5-HT treatment increased 5-HT receptor 7-dependent $D D X 3 X$ promoter activity, along with downstream expression, to induce innate immunity against hepatitis B virus (HBV) infection [68]. Activation of innate immune response through the TBK1/IKK $\varepsilon /$ IRF3 signaling axis was also observed by the ginsenoside Rg3 stimulus, which increased Akt-p53-dependent DD3X promoter transactivation and its expression level [69]. A microarray analysis also showed fibronectin 1 could increase the expression of human DDX3X mRNA in cultured HUVEC cells [70]. AGR2, a member of the protein disulfide isomerase family, is also a proto-oncogene, and the extracellular form of AGR2 has been seen to induce tumor metastasis in various in vivo animal models. The bindings of human AGR2 protein and human DDX3X protein have been characterized, though the molecular mechanism(s) remain to be further explored [71]. Furthermore, interactions of DDX3X with TNF [72], TGF $\beta 1$ [73], and Fibronectin 1 [74], proven by affinity chromatography, have been reported. The effects of small compounds on DDX3X in various cancers are represented (Figure 3).
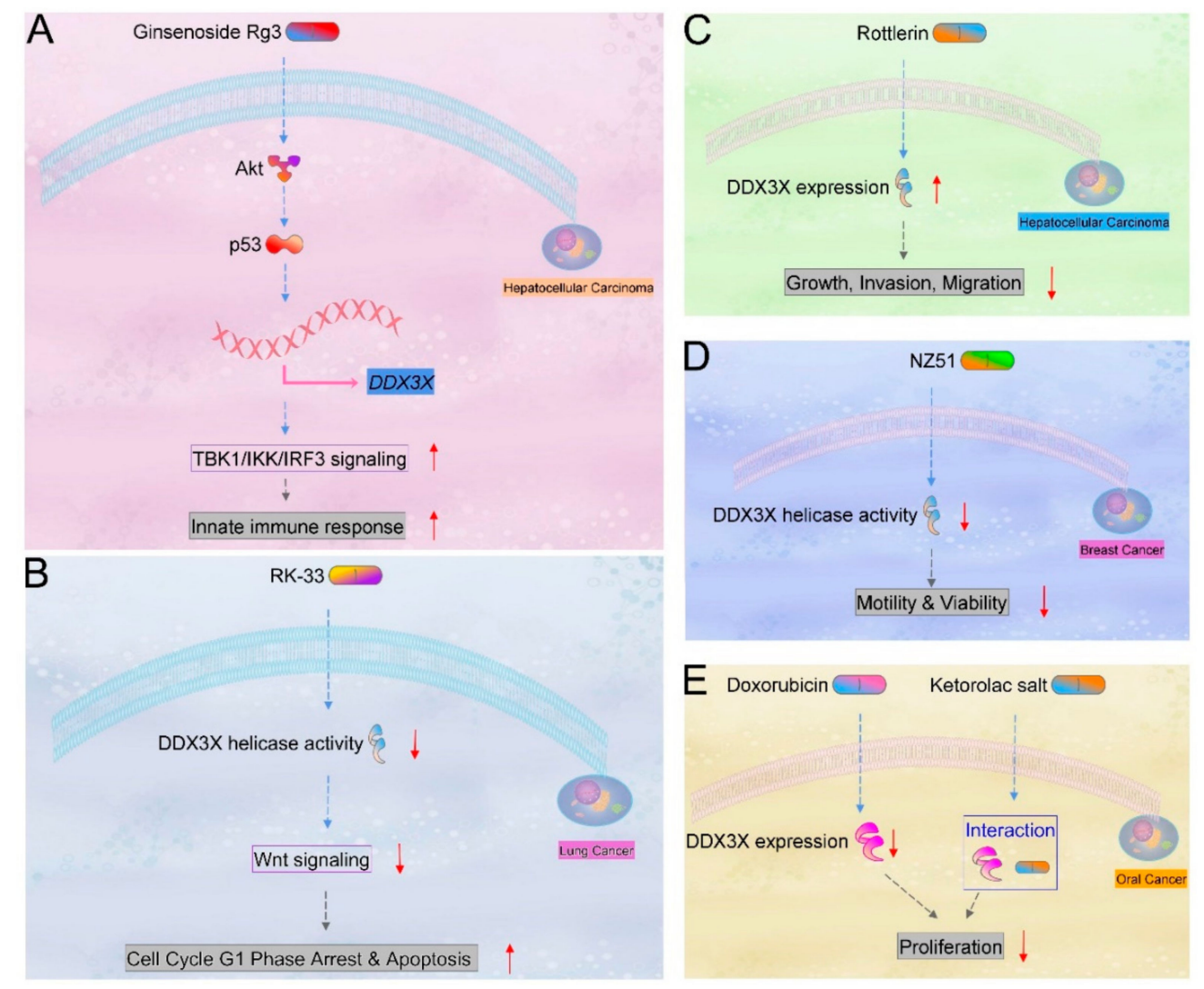

Figure 3. Diagram of DDX $3 X$ alternations by compounds. The changes in DDX3X activity and expression level along with downstream signaling upon (A) Ginsenoside Rg3, (B) RK-33, (C) Rottlerin, (D) NZ51, or (E) doxorubicin addition in various types of cancer are represented. 


\section{Discussion and Conclusions}

We summarized and integrated published references and data from an in silico analysis to clarify the relative expression levels of DDX3X in multiple types of cancers. In addition to the clinical outcomes associated with DDX3X levels observed on a pancancer scale, the pivotal roles of DDX3X in modulating processes relevant to cancer progression, including cancer cell proliferation, metastasis, drug resistance, and cancer stemness, were also illustrated, along with the upstream regulators, small molecules, and cytokines, from extracellular space. Notably, the differential expression of DDX3X at the RNA level in specific cancer types further highlights the value of mechanistic studies regarding alterations in transcriptional activity and RNA stability. In contrast, evaluations of prognostic significance revealed a discrepancy in several types of cancers, indicating that the impact of DDX3X on those tumor types remains to be explored and additional evidence is required. Furthermore, the differences resulting from variations in analytic platforms and endpoint designs of studies should be considered. Actually, prognostic power is judged by the various number of cases enrolled in each cohort.

Funding: This study was funded by Chang Gung Memorial Hospital, Linkou (CMRPG3G0613, CMRPG3J1411, CMRPG3J1412, and CMRPG3J1413) and the Ministry of Science and Technology (1072314-B-182A-158-MY3), Taiwan.

Acknowledgments: I am grateful for help obtained from the Genomic Medicine Core Laboratory, Chang Gung Memorial Hospital, Linkou, Taiwan.

Conflicts of Interest: The authors declare no conflict of interest.

\section{References}

1. Song, H.; Ji, X. The mechanism of RNA duplex recognition and unwinding by DEAD-box helicase DDX3X. Nat. Commun. 2019, 10, 3085. [CrossRef]

2. Zhou, Z.; Licklider, L.J.; Gygi, S.P.; Reed, R. Comprehensive proteomic analysis of the human spliceosome. Nature 2002, 419, 182-185. [CrossRef] [PubMed]

3. Yedavalli, V.S.; Neuveut, C.; Chi, Y.H.; Kleiman, L.; Jeang, K.T. Requirement of DDX3 DEAD box RNA helicase for HIV-1 Rev-RRE export function. Cell 2004, 119, 381-392. [CrossRef] [PubMed]

4. Chao, C.H.; Chen, C.M.; Cheng, P.L.; Shih, J.W.; Tsou, A.P.; Lee, Y.H. DDX3, a DEAD box RNA helicase with tumor growth-suppressive property and transcriptional regulation activity of the p21waf1/cip1 promoter, is a candidate tumor suppressor. Cancer Res. 2006, 66, 6579-6588. [CrossRef] [PubMed]

5. Chuang, R.Y.; Weaver, P.L.; Liu, Z.; Chang, T.H. Requirement of the DEAD-Box protein ded1p for messenger RNA translation. Science 1997, 275, 1468-1471. [CrossRef] [PubMed]

6. Shih, J.W.; Tsai, T.Y.; Chao, C.H.; Wu Lee, Y.H. Candidate tumor suppressor DDX3 RNA helicase specifically represses cap-dependent translation by acting as an eIF4E inhibitory protein. Oncogene 2008, 27, 700-714. [CrossRef]

7. Lee, C.S.; Dias, A.P.; Jedrychowski, M.; Patel, A.H.; Hsu, J.L.; Reed, R. Human DDX3 functions in translation and interacts with the translation initiation factor eIF3. Nucleic Acids Res. 2008, 36, 4708-4718. [CrossRef]

8. Cheng, W.; Wang, S.; Zhang, Z.; Morgens, D.W.; Hayes, L.R.; Lee, S.; Portz, B.; Xie, Y.; Nguyen, B.V.; Haney, M.S.; et al. CRISPR-Cas9 Screens Identify the RNA Helicase DDX3X as a Repressor of C9ORF72 (GGGGCC)n Repeat-Associated Non-AUG Translation. Neuron 2019, 104, 885-898. [CrossRef]

9. Kent, W.J.; Sugnet, C.W.; Furey, T.S.; Roskin, K.M.; Pringle, T.H.; Zahler, A.M.; Haussler, D. The human genome browser at UCSC. Genome Res. 2002, 12, 996-1006. [CrossRef]

10. Pugh, T.J.; Weeraratne, S.D.; Archer, T.C.; Pomeranz Krummel, D.A.; Auclair, D.; Bochicchio, J.; Carneiro, M.O.; Carter, S.L.; Cibulskis, K.; Erlich, R.L.; et al. Medulloblastoma exome sequencing uncovers subtype-specific somatic mutations. Nature 2012, 488, 106-110. [CrossRef]

11. Robinson, G.; Parker, M.; Kranenburg, T.A.; Lu, C.; Chen, X.; Ding, L.; Phoenix, T.N.; Hedlund, E.; Wei, L.; Zhu, X.; et al. Novel mutations target distinct subgroups of medulloblastoma. Nature 2012, 488, 43-48. [CrossRef] [PubMed]

12. Wang, L.; Lawrence, M.S.; Wan, Y.; Stojanov, P.; Sougnez, C.; Stevenson, K.; Werner, L.; Sivachenko, A.; DeLuca, D.S.; Zhang, L.; et al. SF3B1 and other novel cancer genes in chronic lymphocytic leukemia. N. Engl. J. Med. 2011, 365, 2497-2506. [CrossRef] [PubMed] 
13. Ojha, J.; Secreto, C.R.; Rabe, K.G.; Van Dyke, D.L.; Kortum, K.M.; Slager, S.L.; Shanafelt, T.D.; Fonseca, R.; Kay, N.E.; Braggio, E. Identification of recurrent truncated DDX3X mutations in chronic lymphocytic leukaemia. Br. J. Haematol. 2015, 169, 445-448. [CrossRef] [PubMed]

14. Jiang, L.; Gu, Z.H.; Yan, Z.X.; Zhao, X.; Xie, Y.Y.; Zhang, Z.G.; Pan, C.M.; Hu, Y.; Cai, C.P.; Dong, Y.; et al. Exome sequencing identifies somatic mutations of DDX3X in natural killer/T-cell lymphoma. Nat. Genet. 2015, 47, 1061-1066. [CrossRef] [PubMed]

15. Cheng, F.; Liu, C.; Lin, C.C.; Zhao, J.; Jia, P.; Li, W.H.; Zhao, Z. A Gene Gravity Model for the Evolution of Cancer Genomes: A Study of 3,000 Cancer Genomes across 9 Cancer Types. PLoS Comput. Biol. 2015, 11, e1004497. [CrossRef]

16. Rocak, S.; Linder, P. DEAD-box proteins: The driving forces behind RNA metabolism. Nat. Rev. Mol. Cell Biol. 2004, 5, 232-241. [CrossRef]

17. Fuller-Pace, F.V. DEAD box RNA helicase functions in cancer. RNA Biol. 2013, 10, 121-132. [CrossRef]

18. Cannizzaro, E.; Bannister, A.J.; Han, N.; Alendar, A.; Kouzarides, T. DDX3X RNA helicase affects breast cancer cell cycle progression by regulating expression of KLF4. FEBS Lett. 2018, 592, 2308-2322. [CrossRef]

19. Herdy, B.; Mayer, C.; Varshney, D.; Marsico, G.; Murat, P.; Taylor, C.; D’Santos, C.; Tannahill, D.; Balasubramanian, S. Analysis of NRAS RNA G-quadruplex binding proteins reveals DDX3X as a novel interactor of cellular G-quadruplex containing transcripts. Nucleic Acids Res. 2018, 46, 11592-11604. [CrossRef]

20. Wu, D.W.; Lin, P.L.; Wang, L.; Huang, C.C.; Lee, H. The YAP1/SIX2 axis is required for DDX3-mediated tumor aggressiveness and cetuximab resistance in KRAS-wild-type colorectal cancer. Theranostics 2017, 7, 1114-1132. [CrossRef]

21. Heerma van Voss, M.R.; Schrijver, W.A.; Ter Hoeve, N.D.; Hoefnagel, L.D.; Manson, Q.F.; van der Wall, E.; Raman, V.; van Diest, P.J. The prognostic effect of DDX3 upregulation in distant breast cancer metastases. Clin. Exp. Metastasis 2017, 34, 85-92. [CrossRef] [PubMed]

22. Liang, S.; Yang, Z.; Li, D.; Miao, X.; Yang, L.; Zou, Q.; Yuan, Y. The Clinical and Pathological Significance of Nectin-2 and DDX3 Expression in Pancreatic Ductal Adenocarcinomas. Dis. Mark. 2015, 2015, 379568. [CrossRef] [PubMed]

23. Xie, M.; Vesuna, F.; Tantravedi, S.; Bol, G.M.; Heerma van Voss, M.R.; Nugent, K.; Malek, R.; Gabrielson, K.; van Diest, P.J.; Tran, P.T.; et al. RK-33 Radiosensitizes Prostate Cancer Cells by Blocking the RNA Helicase DDX3. Cancer Res. 2016, 76, 6340-6350. [CrossRef]

24. Heerma van Voss, M.R.; Vesuna, F.; Trumpi, K.; Brilliant, J.; Berlinicke, C.; de Leng, W.; Kranenburg, O.; Offerhaus, G.J.; Burger, H.; van der Wall, E.; et al. Identification of the DEAD box RNA helicase DDX3 as a therapeutic target in colorectal cancer. Oncotarget 2015, 6, 28312-28326. [CrossRef] [PubMed]

25. Zhu, J.; Sanborn, J.Z.; Benz, S.; Szeto, C.; Hsu, F.; Kuhn, R.M.; Karolchik, D.; Archie, J.; Lenburg, M.E.; Esserman, L.J.; et al. The UCSC Cancer Genomics Browser. Nat. Methods 2009, 6, 239-240. [CrossRef]

26. Wu, D.W.; Lin, P.L.; Cheng, Y.W.; Huang, C.C.; Wang, L.; Lee, H. DDX3 enhances oncogenic KRASinduced tumor invasion in colorectal cancer via the betacatenin/ZEB1 axis. Oncotarget 2016, 7, 22687-22699. [CrossRef]

27. He, T.Y.; Wu, D.W.; Lin, P.L.; Wang, L.; Huang, C.C.; Chou, M.C.; Lee, H. DDX3 promotes tumor invasion in colorectal cancer via the CK1epsilon/Dvl2 axis. Sci. Rep. 2016, 6, 21483. [CrossRef]

28. Heerma van Voss, M.R.; Vesuna, F.; Bol, G.M.; Afzal, J.; Tantravedi, S.; Bergman, Y.; Kammers, K.; Lehar, M.; Malek, R.; Ballew, M.; et al. Targeting mitochondrial translation by inhibiting DDX3: A novel radiosensitization strategy for cancer treatment. Oncogene 2018, 37, 63-74. [CrossRef]

29. Heerma van Voss, M.R.; Vesuna, F.; Bol, G.M.; Meeldijk, J.; Raman, A.; Offerhaus, G.J.; Buerger, H.; Patel, A.H.; van der Wall, E.; van Diest, P.J.; et al. Nuclear DDX3 expression predicts poor outcome in colorectal and breast cancer. OncoTargets Ther. 2017, 10, 3501-3513. [CrossRef]

30. Chen, H.H.; Yu, H.I.; Yang, M.H.; Tarn, W.Y. DDX3 Activates CBC-eIF3-Mediated Translation of uORF-Containing Oncogenic mRNAs to Promote Metastasis in HNSCC. Cancer Res. 2018, 78, 4512-4523. [CrossRef]

31. Wu, D.W.; Lee, M.C.; Wang, J.; Chen, C.Y.; Cheng, Y.W.; Lee, H. DDX3 loss by p53 inactivation promotes tumor malignancy via the MDM2/Slug/E-cadherin pathway and poor patient outcome in non-small-cell lung cancer. Oncogene 2014, 33, 1515-1526. [CrossRef] [PubMed] 
32. Su, C.Y.; Lin, T.C.; Lin, Y.F.; Chen, M.H.; Lee, C.H.; Wang, H.Y.; Lee, Y.C.; Liu, Y.P.; Chen, C.L.; Hsiao, M. DDX3 as a strongest prognosis marker and its downregulation promotes metastasis in colorectal cancer. Oncotarget 2015, 6, 18602-18612. [CrossRef] [PubMed]

33. Uhlen, M.; Fagerberg, L.; Hallstrom, B.M.; Lindskog, C.; Oksvold, P.; Mardinoglu, A.; Sivertsson, A.; Kampf, C.; Sjostedt, E.; Asplund, A.; et al. Proteomics. Tissue-based map of the human proteome. Science 2015, 347, 1260419. [CrossRef] [PubMed]

34. Uhlen, M.; Oksvold, P.; Fagerberg, L.; Lundberg, E.; Jonasson, K.; Forsberg, M.; Zwahlen, M.; Kampf, C.; Wester, K.; Hober, S.; et al. Towards a knowledge-based Human Protein Atlas. Nat. Biotechnol. 2010, 28, 1248-1250. [CrossRef] [PubMed]

35. Thul, P.J.; Akesson, L.; Wiking, M.; Mahdessian, D.; Geladaki, A.; Ait Blal, H.; Alm, T.; Asplund, A.; Bjork, L.; Breckels, L.M.; et al. A subcellular map of the human proteome. Science 2017, 356. [CrossRef]

36. Uhlen, M.; Zhang, C.; Lee, S.; Sjostedt, E.; Fagerberg, L.; Bidkhori, G.; Benfeitas, R.; Arif, M.; Liu, Z.; Edfors, F.; et al. A pathology atlas of the human cancer transcriptome. Science 2017, 357. [CrossRef]

37. Uhlen, M.; Bjorling, E.; Agaton, C.; Szigyarto, C.A.; Amini, B.; Andersen, E.; Andersson, A.C.; Angelidou, P.; Asplund, A.; Asplund, C.; et al. A human protein atlas for normal and cancer tissues based on antibody proteomics. Mol. Cell. Proteom. 2005, 4, 1920-1932. [CrossRef]

38. Aguirre-Gamboa, R.; Gomez-Rueda, H.; Martinez-Ledesma, E.; Martinez-Torteya, A.; Chacolla-Huaringa, R.; Rodriguez-Barrientos, A.; Tamez-Pena, J.G.; Trevino, V. SurvExpress: An online biomarker validation tool and database for cancer gene expression data using survival analysis. PLoS ONE 2013, 8, e74250. [CrossRef]

39. Gyorffy, B.; Schafer, R. Meta-analysis of gene expression profiles related to relapse-free survival in 1,079 breast cancer patients. Breast Cancer Res. Treat. 2009, 118, 433-441. [CrossRef]

40. Botlagunta, M.; Vesuna, F.; Mironchik, Y.; Raman, A.; Lisok, A.; Winnard, P., Jr.; Mukadam, S.; Van Diest, P.; Chen, J.H.; Farabaugh, P.; et al. Oncogenic role of DDX3 in breast cancer biogenesis. Oncogene 2008, 27, 3912-3922. [CrossRef]

41. Bol, G.M.; Vesuna, F.; Xie, M.; Zeng, J.; Aziz, K.; Gandhi, N.; Levine, A.; Irving, A.; Korz, D.; Tantravedi, S.; et al. Targeting DDX3 with a small molecule inhibitor for lung cancer therapy. EMBO Mol. Med. 2015, 7, 648-669. [CrossRef] [PubMed]

42. Xie, M.; Vesuna, F.; Botlagunta, M.; Bol, G.M.; Irving, A.; Bergman, Y.; Hosmane, R.S.; Kato, Y.; Winnard, P.T., Jr.; Raman, V. NZ51, a ring-expanded nucleoside analog, inhibits motility and viability of breast cancer cells by targeting the RNA helicase DDX3. Oncotarget 2015, 6, 29901-29913. [CrossRef] [PubMed]

43. You, S.; Wang, F.; Hu, Q.; Li, P.; Zhang, C.; Yu, Y.; Zhang, Y.; Li, Q.; Bao, Q.; Liu, P.; et al. Abnormal expression of YEATS4 associates with poor prognosis and promotes cell proliferation of hepatic carcinoma cell by regulation the TCEA1/DDX3 axis. Am. J. Cancer Res. 2018, 8, 2076-2087. [PubMed]

44. Chan, C.H.; Chen, C.M.; Lee, Y.W.; You, L.R. DNA Damage, Liver Injury, and Tumorigenesis: Consequences of DDX3X Loss. Mol. Cancer Res. 2019, 17, 555-566. [CrossRef]

45. Wang, Z.; Shen, G.H.; Xie, J.M.; Li, B.; Gao, Q.G. Rottlerin upregulates DDX3 expression in hepatocellular carcinoma. Biochem. Biophys. Res. Commun. 2018, 495, 1503-1509. [CrossRef]

46. Wu, D.W.; Liu, W.S.; Wang, J.; Chen, C.Y.; Cheng, Y.W.; Lee, H. Reduced p21(WAF1/CIP1) via alteration of p53-DDX3 pathway is associated with poor relapse-free survival in early-stage human papillomavirus-associated lung cancer. Clin. Cancer Res. 2011, 17, 1895-1905. [CrossRef]

47. Chen, W.J.; Wang, W.T.; Tsai, T.Y.; Li, H.K.; Lee, Y.W. DDX3 localizes to the centrosome and prevents multipolar mitosis by epigenetically and translationally modulating p53 expression. Sci. Rep. 2017, 7, 9411. [CrossRef]

48. Bol, G.M.; Raman, V.; van der Groep, P.; Vermeulen, J.F.; Patel, A.H.; van der Wall, E.; van Diest, P.J. Expression of the RNA helicase DDX3 and the hypoxia response in breast cancer. PLoS ONE 2013, 8, e63548. [CrossRef]

49. Phung, B.; Ciesla, M.; Sanna, A.; Guzzi, N.; Beneventi, G.; Cao Thi Ngoc, P.; Lauss, M.; Cabrita, R.; Cordero, E.; Bosch, A.; et al. The X-Linked DDX3X RNA Helicase Dictates Translation Reprogramming and Metastasis in Melanoma. Cell Rep. 2019, 27, 3573-3586. [CrossRef]

50. Vellky, J.E.; Ricke, E.A.; Huang, W.; Ricke, W.A. Expression and Localization of DDX3 in Prostate Cancer Progression and Metastasis. Am. J. Pathol. 2019, 189, 1256-1267. [CrossRef]

51. Chen, H.H.; Yu, H.I.; Cho, W.C.; Tarn, W.Y. DDX3 modulates cell adhesion and motility and cancer cell metastasis via Rac1-mediated signaling pathway. Oncogene 2015, 34, 2790-2800. [CrossRef] [PubMed] 
52. Yang, F.; Fang, E.; Mei, H.; Chen, Y.; Li, H.; Li, D.; Song, H.; Wang, J.; Hong, M.; Xiao, W.; et al. Cis-Acting circ-CTNNB1 Promotes beta-Catenin Signaling and Cancer Progression via DDX3-Mediated Transactivation of YY1. Cancer Res. 2019, 79, 557-571. [CrossRef] [PubMed]

53. Li, H.K.; Mai, R.T.; Huang, H.D.; Chou, C.H.; Chang, Y.A.; Chang, Y.W.; You, L.R.; Chen, C.M.; Lee, Y.H. DDX3 Represses Stemness by Epigenetically Modulating Tumor-suppressive miRNAs in Hepatocellular Carcinoma. Sci. Rep. 2016, 6, 28637. [CrossRef] [PubMed]

54. Yu, H.; Liu, Y.; Niu, C.; Cheng, Y. Diosgenin increased DDX3 expression in hepatocellular carcinoma. Am. J. Transl. Res. 2018, 10, 3590-3599. [PubMed]

55. Arvaniti, K.; Papadioti, A.; Kinigopoulou, M.; Theodorou, V.; Skobridis, K.; Tsiotis, G. Proteome Changes Induced by Imatinib and Novel Imatinib Derivatives in K562 Human Chronic Myeloid Leukemia Cells. Proteomes 2014, 2, 363-381. [CrossRef] [PubMed]

56. Nozaki, K.; Kagamu, H.; Shoji, S.; Igarashi, N.; Ohtsubo, A.; Okajima, M.; Miura, S.; Watanabe, S.; Yoshizawa, H.; Narita, I. DDX3X induces primary EGFR-TKI resistance based on intratumor heterogeneity in lung cancer cells harboring EGFR-activating mutations. PLoS ONE 2014, 9, e111019. [CrossRef]

57. Kerr, C.L.; Bol, G.M.; Vesuna, F.; Raman, V. Targeting RNA helicase DDX3 in stem cell maintenance and teratoma formation. Genes Cancer 2019, 10, 11-20. [CrossRef]

58. Huang, M.; Tailor, J.; Zhen, Q.; Gillmor, A.H.; Miller, M.L.; Weishaupt, H.; Chen, J.; Zheng, T.; Nash, E.K.; McHenry, L.K.; et al. Engineering Genetic Predisposition in Human Neuroepithelial Stem Cells Recapitulates Medulloblastoma Tumorigenesis. Cell Stem Cell 2019, 25, 433-446. [CrossRef]

59. Radi, M.; Falchi, F.; Garbelli, A.; Samuele, A.; Bernardo, V.; Paolucci, S.; Baldanti, F.; Schenone, S.; Manetti, F.; Maga, G.; et al. Discovery of the first small molecule inhibitor of human DDX3 specifically designed to target the RNA binding site: Towards the next generation HIV-1 inhibitors. Bioorgan. Med. Chem. Lett. 2012, 22, 2094-2098. [CrossRef]

60. Botlagunta, M.; Kollapalli, B.; Kakarla, L.; Gajarla, S.P.; Gade, S.P.; Dadi, C.L.; Penumadu, A.; Javeed, S. In vitro anti-cancer activity of doxorubicin against human RNA helicase, DDX3. Bioinformation 2016, 12, 347-353. [CrossRef]

61. Samal, S.K.; Routray, S.; Veeramachaneni, G.K.; Dash, R.; Botlagunta, M. Ketorolac salt is a newly discovered DDX3 inhibitor to treat oral cancer. Sci. Rep. 2015, 5, 9982. [CrossRef] [PubMed]

62. Zhang, Z.; Lei, A.; Xu, L.; Chen, L.; Chen, Y.; Zhang, X.; Gao, Y.; Yang, X.; Zhang, M.; Cao, Y. Similarity in gene-regulatory networks suggests that cancer cells share characteristics of embryonic neural cells. J. Biol. Chem. 2017, 292, 12842-12859. [CrossRef] [PubMed]

63. Brai, A.; Ronzini, S.; Riva, V.; Botta, L.; Zamperini, C.; Borgini, M.; Trivisani, C.I.; Garbelli, A.; Pennisi, C.; Boccuto, A.; et al. Synthesis and Antiviral Activity of Novel 1,3,4-Thiadiazole Inhibitors of DDX3X. Molecules 2019, 24. [CrossRef] [PubMed]

64. Somma, D.; Mastrovito, P.; Grieco, M.; Lavorgna, A.; Pignalosa, A.; Formisano, L.; Salzano, A.M.; Scaloni, A.; Pacifico, F.; Siebenlist, U.; et al. CIKS/DDX3X interaction controls the stability of the Zc3h12a mRNA induced by IL-17. J. Immunol. 2015, 194, 3286-3294. [CrossRef]

65. Matsushita, K.; Takeuchi, O.; Standley, D.M.; Kumagai, Y.; Kawagoe, T.; Miyake, T.; Satoh, T.; Kato, H.; Tsujimura, T.; Nakamura, H.; et al. Zc3h12a is an RNase essential for controlling immune responses by regulating mRNA decay. Nature 2009, 458, 1185-1190. [CrossRef]

66. Mizgalska, D.; Wegrzyn, P.; Murzyn, K.; Kasza, A.; Koj, A.; Jura, J.; Jarzab, B. Interleukin-1-inducible MCPIP protein has structural and functional properties of RNase and participates in degradation of IL-1beta mRNA. FEBS J. 2009, 276, 7386-7399. [CrossRef]

67. Liang, J.; Saad, Y.; Lei, T.; Wang, J.; Qi, D.; Yang, Q.; Kolattukudy, P.E.; Fu, M. MCP-induced protein 1 deubiquitinates TRAF proteins and negatively regulates JNK and NF-kappaB signaling. J. Exp. Med. 2010, 207, 2959-2973. [CrossRef]

68. Kang, L.J.; Nguyen, K.V.A.; Eom, S.; Choi, Y.J.; Nguyen, C.N.; Lee, J.; Kim, C.; Lee, S.; Lee, S.G.; Lee, J.H. Stimulating DDX3 expression by serotonin 5-HT receptor 7 through phosphorylation of p53 via the AC-PKA-ERK signaling pathway. J. Cell. Biochem. 2019, 120, 18193-18208. [CrossRef]

69. Choi, Y.J.; Kang, L.J.; Lee, S.G. Stimulation of DDX3 expression by ginsenoside Rg3 through the Akt/p53 pathway activates the innate immune response via TBK1/IKKepsilon/IRF3 signalling. Curr. Med. Chem. 2014, 21, 1050-1060. [CrossRef] 
70. Orecchia, A.; Mettouchi, A.; Uva, P.; Simon, G.C.; Arcelli, D.; Avitabile, S.; Ragone, G.; Meneguzzi, G.; Pfenninger, K.H.; Zambruno, G.; et al. Endothelial cell adhesion to soluble vascular endothelial growth factor receptor-1 triggers a cell dynamic and angiogenic phenotype. FASEB J. 2014, 28, 692-704. [CrossRef]

71. Tiemann, K.; Garri, C.; Lee, S.B.; Malihi, P.D.; Park, M.; Alvarez, R.M.; Yap, L.P.; Mallick, P.; Katz, J.E.; Gross, M.E.; et al. Loss of ER retention motif of AGR2 can impact mTORC signaling and promote cancer metastasis. Oncogene 2019, 38, 3003-3018. [CrossRef] [PubMed]

72. Kupka, S.; De Miguel, D.; Draber, P.; Martino, L.; Surinova, S.; Rittinger, K.; Walczak, H. SPATA2-Mediated Binding of CYLD to HOIP Enables CYLD Recruitment to Signaling Complexes. Cell Rep. 2016, 16, 2271-2280. [CrossRef] [PubMed]

73. Rosenbluh, J.; Mercer, J.; Shrestha, Y.; Oliver, R.; Tamayo, P.; Doench, J.G.; Tirosh, I.; Piccioni, F.; Hartenian, E.; Horn, H.; et al. Genetic and Proteomic Interrogation of Lower Confidence Candidate Genes Reveals Signaling Networks in beta-Catenin-Active Cancers. Cell Syst. 2016, 3, 302-316. [CrossRef] [PubMed]

74. Humphries, J.D.; Byron, A.; Bass, M.D.; Craig, S.E.; Pinney, J.W.; Knight, D.; Humphries, M.J. Proteomic analysis of integrin-associated complexes identifies RCC2 as a dual regulator of Rac1 and Arf6. Sci. Signal. 2009, 2, ra51. [CrossRef]

(C) 2019 by the author. Licensee MDPI, Basel, Switzerland. This article is an open access article distributed under the terms and conditions of the Creative Commons Attribution (CC BY) license (http://creativecommons.org/licenses/by/4.0/). 